\title{
Effect of $\mathrm{CeO}_{2}$ nanoparticles on Microstructure and Hardness of A6063 Aluminum
} Alloy.

\author{
M. L. Camacho-Rios ${ }^{1}$, A. Saenz-Trevizo ${ }^{1}$, D. Lardizabal-Gutierrez ${ }^{1}$, H. M. Medrano-Prieto ${ }^{1}$, I.
} Estrada-Guel $^{1}$, C.G. Garay-Reyes ${ }^{1}$ and R. Martínez-Sánchez ${ }^{1}$

${ }^{1}$ Centro de Investigación en Materiales Avanzados (CIMAV), Laboratorio Nacional de Nanotecnología, Miguel de Cervantes No. 120, 31136, Chihuahua, Chih., México.

Aluminium alloy 6063 (A6063) has been identified as a marine grade alloys because of their excellent corrosion resistance in marine environment. A6063 demand special attention and the need for further improvement in its mechanical properties for better performance in service [1]. Incorporating nanoparticles of metal-oxides the mechanical properties are enhanced. Dispersion of nanoparticles in a metal matrix have positive effect on mechanical properties.

This work is focused on the potential effect of Ceria $\left(\mathrm{CeO}_{2}\right)$ particles with nano size and different morphologies on the strengthening of the A6063. The morphological control of Ceria nanoparticles has received much attention for being particularly important. Morphology have an important influence in the chemical and physical properties. Additionally, the addition of Ceria nanoparticles with different morphologies has not been explored in the A6063.

Nanoparticles of Ceria with different morphologies (square and round) were obtained by hydrothermal synthesis, square shape was obtained at $160{ }^{\circ} \mathrm{C}$ and round shape at $190^{\circ} \mathrm{C}$ [2]. It was dispersed with different concentration $(0.25,0.50 .75$ y $1.0 \mathrm{wt}$. \%) into A6063 by mechanical milling in high energy Spex mill during $2 \mathrm{~h}$, argon was used as the milling atmosphere and methanol was used as process control agent, consolidated products were obtained by pressing the powder mixtures for 2 minutes at $1500 \mathrm{MPa}$ in uniaxial load, consolidated samples were sintered at $570{ }^{\circ} \mathrm{C}$ for $3 \mathrm{~h}$ under argon atmosphere. Microstructural and hardness analyses were conduced in samples with and without Ceria additions, in order to determine the effect of the Ceria into the A6063.

The results show square Ceria shape fig. 1a, has a better homogeneous distribution into A6063 matrix fig. $2 \mathrm{a}$, in comparison to Ceria round fig.2b.The strengthening precipitates in 6xxx series alloys are based on magnesium silicide $\mathrm{Mg}-\mathrm{Si}$ [3], fig. 3b shows a poor quantity of precipitates $\mathrm{Mg}-\mathrm{Si}$ in comparison to fig.3a. The excessive delamination and voids in A6063 with round Ceria, caused a decrement in mechanical properties (fig.4). It may be concluded that Ceria square shape at $0.25 \mathrm{wt}$. \% was dispersed into A6063 which shows a significant increase on hardness values, which are presented on Table.1.

\section{References:}

[1] D.A. Isadore et al, Advances in Research. AIR ,5(3) (2015), p.1-7.

[2] G. Jinfeng et al, J. Alloys Compd.689 (2016), p.606-616.

[3] M.J. Couper et al, ICAA-Conference.12th (2010), p.149 -154. 

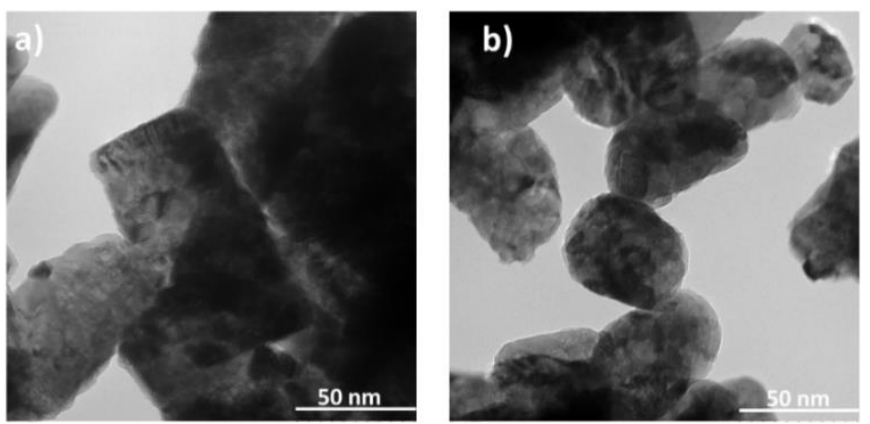

Figure.1 Micrographs TEM mode a) $\mathrm{CeO}_{2}$ square shape and b) $\mathrm{CeO}_{2}$ round shape, before mechanical milling.

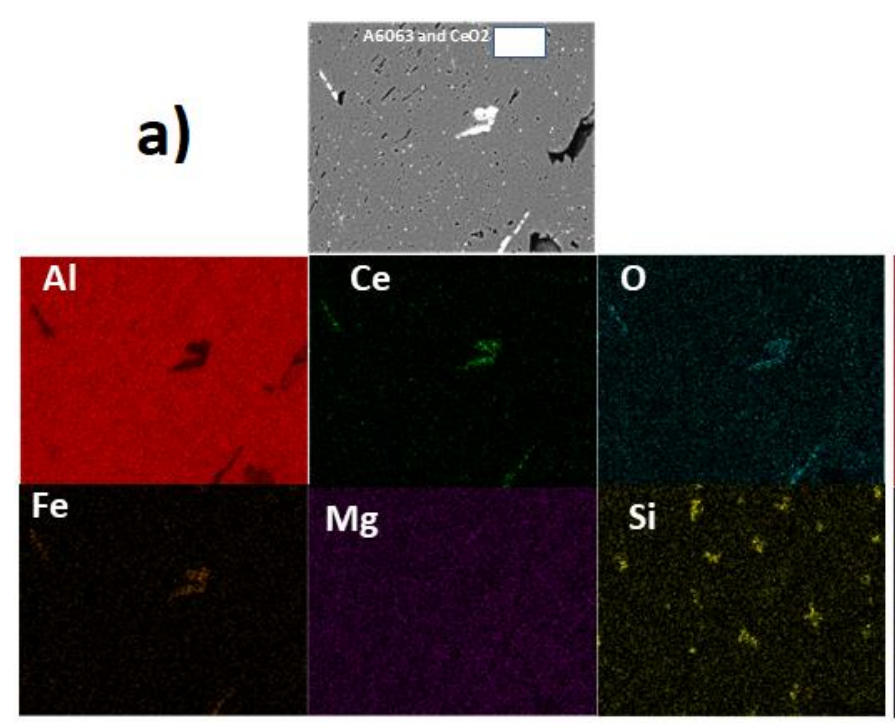

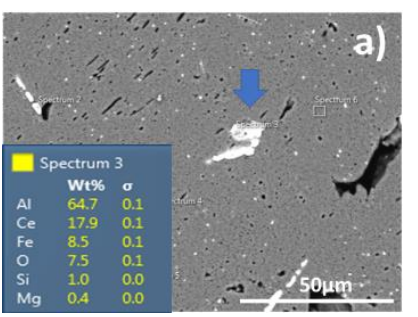

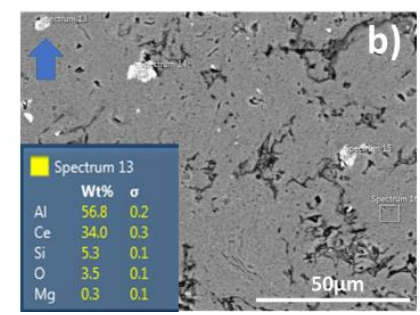

Figure.2 Micrographs SEM BSE-COM mode a) $\mathrm{A} 6063$ with $1.0 \% \mathrm{CeO}_{2}$ square shape and b) A6063 with $\mathrm{CeO}_{2}$ round shape, blue arrows show intermetallic structures.

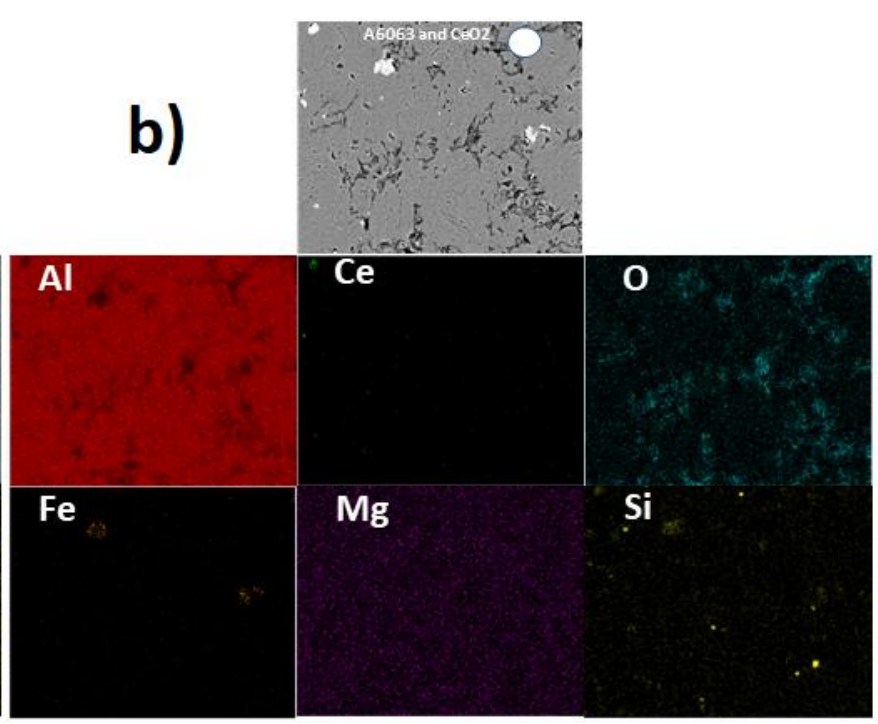

Figure.3 EDS-SEM mappings of $\mathrm{A} 6063$ and $\mathrm{CeO} 2$, a) $\mathrm{CeO}_{2}$ square shape b) $\mathrm{CeO} 2$ round shape, after mechanical milling.

Tabla1. Microhardness of $\mathrm{A6063}$ with $\mathrm{CeO}_{2}$ (square and round)

\begin{tabular}{|l|l|}
\hline \multicolumn{1}{|c|}{ Samples } & \multicolumn{1}{c|}{ Hardness [HV] } \\
\hline A6063 & $83.62 \pm 1.343$ \\
\hline A6063 and $0.25 \% \mathrm{CeO} 2$ & $110.15 \pm 2.52$ \\
\hline A6063 and $0.25 \% \mathrm{CeO} 2$ & $93.54 \pm 1.61$ \\
\hline
\end{tabular}

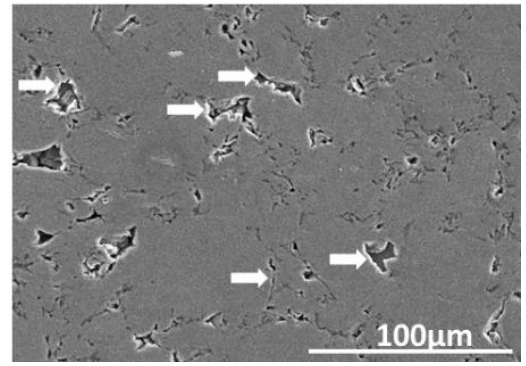

Fig. 4 SEM SE mode image of sintered $\mathrm{A} 6063$ and $0.75 \% \mathrm{CeO}_{2}$ round, white arrows show the delamination and voids. 